\title{
BAPTISTA, Selma. 2006. Una Concepción Trágica de la Cultura. Lima: Fondo Editorial de la Pontificia Universidad Católica del Perú. 276 pp.
}

Zélia Bonamigo O livro Una concepción trágica de la cultura interpreta a realidade do Peru como UFPR um processo histórico, chegando ao contexto das transformações mundiais atuais, desencadeadas pela globalização. Parte das representações intelectuais para problematizar a construção da identidade nacional. Para tanto, realiza uma etnografia do pensamento social reconstruindo as relações que a Antropologia peruana, em suas diversas áreas acadêmicas, desenvolve com a literatura, com a história e com a crítica literária. A autora discute em que medida a problemática cultural peruana se constitui em um estilo de "pensamento antropológico periférico" e de que maneira a existência deste estilo indicaria uma concepção de cultura particular.

Uma de suas referências básicas é o antropólogo Roberto Cardoso de Oliveira que, ao historiar o desenvolvimento da Antropologia em diversas partes do mundo "periférico", propõe a construção do conceito de estilo para analisar a identidade e as diferenças entre as modalidades de antropologias "nacionais". A antinomia centro/periferia é analisada pela autora como forma de compreender a relação entre a disciplina e sua prática, pois se trata de entender o processo transcultural por meio do qual a matriz da antropologia mantém sua identidade, apesar das mudanças sofridas nos diversos países.

Trabalhando no campo da crítica cultural, as trajetórias, vidas e trabalhos de intelectuais peruanos tornam-se possíveis representações, figuras narrativas que, ao serem apreendidas de forma intercultural, revelam como eles próprios pensam e/ou pensaram sua cultura e identidade.

Elegendo, inicialmente, o suicídio de um novelista e antropólogo peruano como uma possível metáfora da tensão entre centro-periferia, procurou na vida e obra de José Maria Arguedas formas intercambiáveis de conhecimento: a ficção, reveladora de sentimentos e emoções articulados pela imaginação, e a descrição etnográfica, unidas na tentativa de superar a antiga tese dualista de enfrentamento entre brancos e índios. Apreende a trajetória de Arguedas a partir da crítica literária, 
percorrendo temas estudados por alguns dos principais críticos literários, desde José Martí até Roberto F. Retamar, chegando aos mais contemporâneos como Antonio Cornejo Polar, Angel Rama, Roland Forgues, Chang-Rodriguez e Edmundo Bendezú, entre outros.

Outro trabalho inspirador na construção da representação do suicídio de Arguedas foi o livro de Marguerite Yourcenar sobre Yukio Mishima, escritor japonês que se suicidou em 1970, um ano depois de Arguedas, em um ritual sepuku. Yourcenar interpreta o suicídio de Mishima como uma alegoria, como uma obra construída no decorrer da vida do autor, mostrando-nos a concretização de um vazio estético, espiritual e existencial, tanto na literatura quanto na vida de Mishima, como conseqüência da perda das referências culturais tradicionais japonesas.

Mas tornou-se necessário superar a visão dualista do binômio centro/periferia, e buscar a possibilidade de um contraponto interno ao próprio movimento da modernidade, em que as situações pós-coloniais pudessem ter alguma relação com a concepção trágica da cultura, hipótese que começava a insinuar-se no trabalho. Ainda que o material pesquisado Ihe indicasse este caráter trágico como a própria radicalização anticapitalista, a autora, temendo uma simplificação teórica, buscou em Walter Benjamin (1984), A Origem do Drama Barroco Alemão, a proposta do barroco como idéia que se atualiza na história, deixando em aberto seu potencial explicativo para possíveis ressonâncias mais contemporâneas da alegoria original discutida no referido trabalho. Neste percurso, a autora considerou importante trabalhar, por um lado, na busca das condições concretas em que uma determinada sociedade, como processo local e periférico, vai se incorporando ao capitalismo, e, por outro, tomar a periferia, além de sua condição geográfica e econômica, também como região intelectual, procurando apreender outras possibilidades interpretativas.

Baptista estabeleceu uma relação entre mito e história, lembrando-nos de que na origem do drama peruano está a tragédia de Atahualpa, ocorrida em novembro de 1532, quando da conquista do Peru pelos espanhóis. Ainda que a captura e morte de Atahualpa em si não se constitua num mito, insere-se na cadeia dos acontecimentos como fatalidade histórica, totalmente plena da idéia de sacrifício, primeiro ingrediente de uma comunidade imaginada.

A inserção da sociedade peruana no movimento do capitalismo internacional é relatada no terceiro capítulo, bem como a origem da auto-reflexão moderna no Peru e a revolução urbana de Lima, quando Mariátegui é citado como aquele que, pela primeira vez na história intelectual do país, mesmo com restrições, consegue propor e buscar a totalidade da nação como característica fundamental da modernidade periférica, pela união das demandas urbanas e camponesas. A autora traz para o texto uma avalanche de informações e autores sobre Lima, com o intuito de verificar as ligações existentes entre a matriz andina e a idéia de uma continuidade trágica.

O quarto capítulo é também povoado por tradições periféricas constituintes de um drama, conforme o pensamento de José Carlos Mariátegui, e de suas imagens polêmicas. No centro da consciência dramática, está a modernidade. A autora constata que há profunda relação entre a formulação da existência de uma matriz andina e sua subseqüente e polêmica percepção como utopia andina, assim como a recolocação de seu significado histórico ao longo do tempo se apresenta envolta em uma tragicidade inerente à própria percepção como utopia andina.

No quinto e sexto capítulos, Baptista realiza uma análise interna da sociedade e da cultura peruanas, a partir 
do que dizem os autores peruanos sobre o desenvolvimento da antropologia no país e de acordo com dados sobre a antropologia acadêmica.

A questão étnica é colocada como base do entendimento das formas com que a etnicidade se apresenta no Peru, e a autora demonstra esta questão a partir das idéias de vários intelectuais peruanos. Para Carlos Ivan Degregori, por exemplo, a debilidade da integração no Peru faz com que as maiorias andinas, populares e provincianas construam sua identidade étnica dando-lhe sentidos insuspeitados. Finalmente a autora relata uma série de mediações, mas prioriza as trajetórias antropológicas de Valcárcel e Arguedas.

A trajetória de Valcárcel é reveladora do início acadêmico da Antropologia no Peru e seu processo de institucionalização relacionado com a Universidade Nacional Maior de San Marcos. Por meio da Etnologia, que ele ajudou a impulsionar, a antiga cultura peruana tornou-se uma realidade etnográfica. Ele criou vários institutos de pesquisa enquanto Ministro de Educação, especialmente o de Etnologia, do qual se tornou o primeiro diretor, tarefa também realizada a partir de 1946, após a criação do Instituto Indígena Peruano, órgão vinculado ao Ministério de Justiça e de Trabalho. Mas Valcárcel começou sua vida intelectual escrevendo literatura, de cunho nitidamente trágico, inflamado, dramático. Desta maneira, a autora vê nesta trajetória um movimento que vai do trágico ao institucional, tornando-se escola de pensamento e estimulando um ressurgimento indígena, que vai ressoar na questão identitária.

José M. Arguedas, ao contrário, desde o início de sua carreira como antropólogo, assumiu cargos administrativos: tornou-se diretor do depto de Folclore e, a partir de 1953, colaborador da Revista do Comitê Interamericano de Folklore Americano. No decorrer da sua vida, sua trajetória vai se encaminhando cada vez mais para a literatura e para uma certa maneira de encarar a realidade do país, de cunho bastante agônico. Enfim, faz, na sua opinião, um percurso contrário ao de Valcárcel. Embora sua obra seja extensa, a autora a toma na perspectiva da hipótese de seu trabalho, no âmbito da concepção trágica da cultura peruana. Sua obra foi e ainda é objeto de intensos estudos. Foi comentada por inúmeros críticos de literatura e de antropologia. Vargas Llosa, por exemplo, fez-Ihe críticas acirradas, vendo-o como um desgarrado, ou seja, entre o espanhol e o índio, um homem apegado a um mundo camponês, repleto de costumes tradicionais, um homem problemático e doente.

Para Llosa, as narrativas de Arguedas acabaram por se tornar um babelismo, metáfora de horror ao progresso, embora o trabalho em seu conjunto emocione por sua compaixão pela miséria material e moral. Estas questões apontam para um possível significado histórico de sua morte, da mesma forma, diz a autora, como Yourcenar pensou a vida e a obra de Yukio Mishima. Mas seus adeptos foram e são muito mais numerosos e elogiosos, como o foram Rama, Forgues e Rowe, entre tantos outros. Arguedas é uma verdadeira tradição no pensamento peruano e, segundo a autora, sua obra capta com extrema sensibilidade o que há de mais permanente na cultura andina, discutindo de modo competente o novo modelo mestiço que irrompeu nas interpretações da cultura peruana como um todo, à sua época.

No sétimo capítulo, a autora reforça a existência de uma matriz andina, trazendo-a aos dias atuais através do trabalho de dois antropólogos: Juan Ossio e Rodrigo Montoya Rojas. Ossio escolheu como objeto de estudo 
o cronista Guamán Poma de Ayala, pelo seu interesse na cultura incaica e, através dos seus estudos na Inglaterra com a orientação de Evans-Pritchard, buscou o sentido do messianismo andino através do funcional-estruturalismo, enfatizando a posição do mito na construção deste pensamento. Por sua vez, Montoya elegeu o cronista Inca Garcilaso de la Veja, e Baptista afirma que seu personagem pode ser pensado como uma dramatis personae, aquele que formulou pela primeira vez perguntas que ainda aguardam respostas. Montoya optou pelo mestiço, aquele que perdeu sua identidade, viveu buscando uma pátria e acabou por criá-la através das palavras. Mas ambos se unem apoiando-se na afirmação da diversidade social e cultural peruana.

A pesquisadora conclui, finalmente, que o estilo da antropologia peruana se expressa como modo específico de representar os conflitos de uma cultura híbrida no contexto de um mundo globalizado, sem ter ultrapassado seus conflitos mais recorrentes, ou seja, a realização de uma inclusão irrestrita, ou, como diz Montoya, a vivência plena de um "socialismo mágico", de uma pátria para todos. 